\title{
Rectal perforation after neoadjuvant chemoradiotherapy for low-lying rectal cancer
}

\author{
Khalil ElGendy
}

Department of Colorectal Surgery, King Fahad Specialist Hospital Dammam, Dammam, Saudi Arabia

Correspondence to Khalil ElGendy,

k.m.elgendy@gmail.com

Accepted 18 December 2014

\section{DESCRIPTION}

A 55-year-old woman was referred to the colorectal surgery unit after receiving long course neoadjuvant chemoradiotherapy (total dose of 45 Gy over 5 weeks) for low-lying rectal adenocarcinoma, $5 \mathrm{~cm}$ from the anal verge, with clinical stage cT3N1M0. The patient reported of lower abdominal pain with diarrhoea and tenesmus during the last few days of the regimen, which continued for the following 4 weeks and were assumed to be related to the neoadjuvant therapy. Preoperative CT of the abdomen and pelvis with contrast for assessment of the tumour response revealed leakage of the contrast into the mesorectum up to peritoneal reflection anteriorly and to the left with suspected rectal perforation adjacent to the rectal tumour, which was on the right side (figure 1). The patient was admitted and offered conservative management in the form of bowel rest and antibiotics. MRI of the pelvis after 3 days revealed the rectal tumour with stage of T3N0, with improvement of the contrast extravasation and could not identify the site of perforation (figure 2). The patient underwent the planned surgery in the form of low anterior resection with diverting loop ileostomy. The pathological staging of the rectal adenocarcinoma was

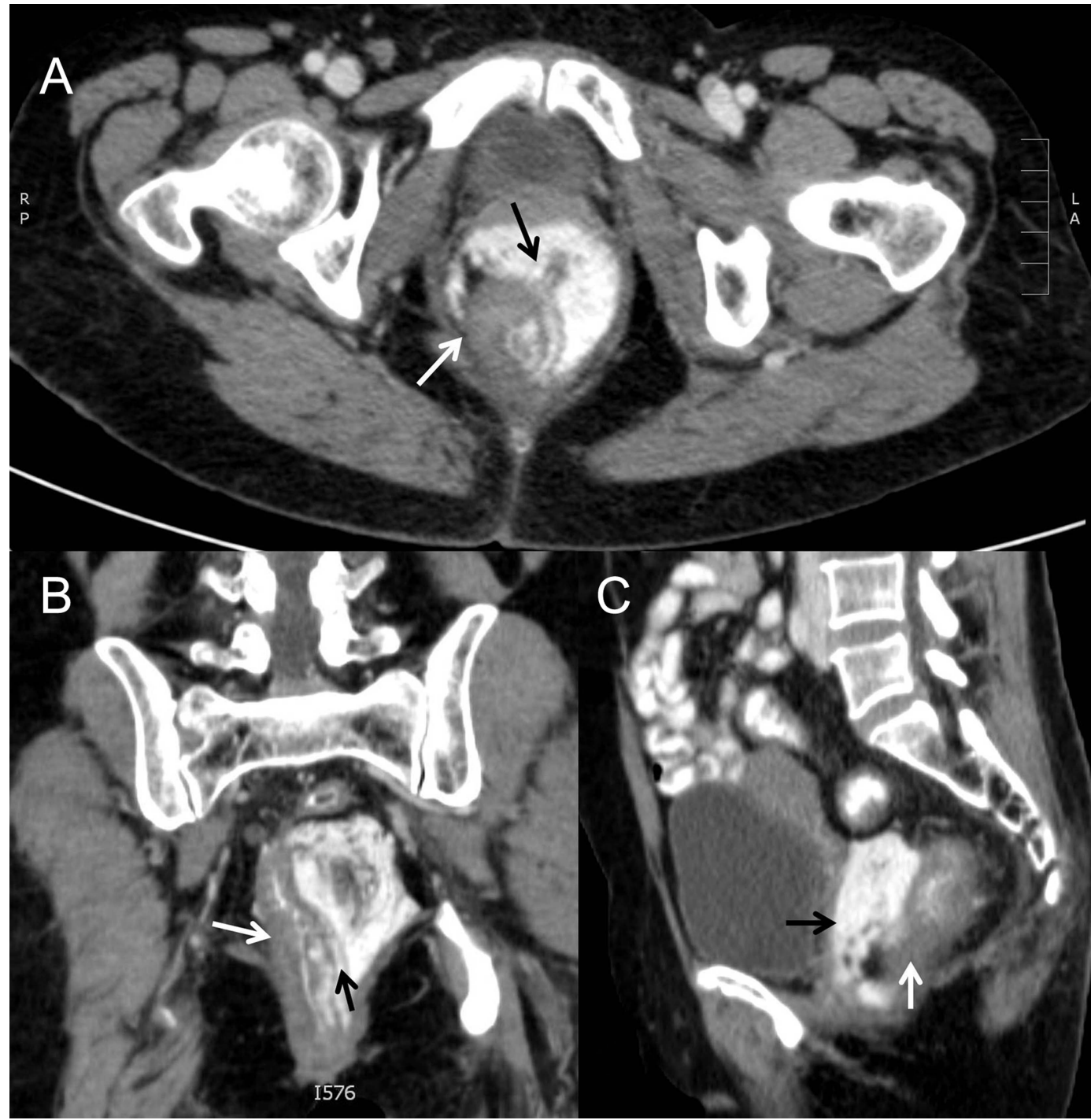

Figure $1 \mathrm{CT}$ of abdomen and pelvis with contrast, showing the rectal mass (white arrows) with the leakage of contrast into the mesorectum at the site suspected of perforation (black arrows) in (A) axial, (B) coronal and (C) sagittal views. 


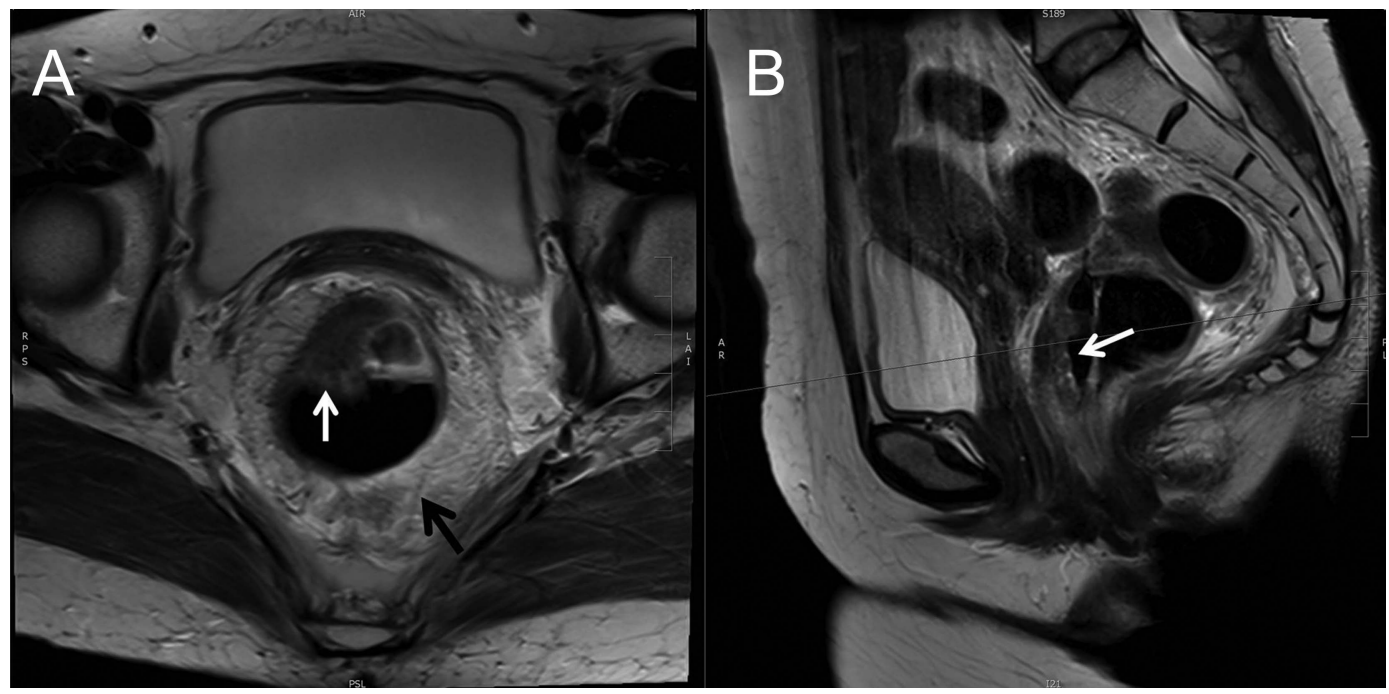

Figure $2 \mathrm{MRI}$ of the pelvis showing the rectal mass (white arrows) with the decrease in extravasation of the contrast in the mesorectum (black arrow) in axial (A) and sagittal (B) views.

pT2N0 with no lymph node involvement of the 13 retrieved with no risk factors including tumour perforation. The perforation was identified in the radiated rectum close to the tumour. The patient received postoperative adjuvant therapy, after which she underwent closure of the temporary stoma. She is currently under surveillance as recommended by the NCCN guidelines. ${ }^{1}$

Neoadjuvant chemoradiotherapy became the standard management for rectal adenocarcinomas with clinical staging other than stage I. Together with total mesorectal excision, it has proven to decrease local recurrence and potentially increase survival. ${ }^{2}$ However, it is associated with morbidity and mortality.

\section{Learning points}

- Neoadjuvant chemoradiotherapy of rectal cancer has many advantages in decreasing local recurrence and improving survival. However, there is a risk of complications, including rare life-threatening rectal tumour perforation. In this case report, the perforation occurred in the irradiated rectum away from the rectal tumour.

- Such occurrence of rectal perforation is important to consider in the consent as well as the choice of diverting stoma in selective cases of rectal cancer. Whether to perform diverting ileostomy before starting neoadjuvant therapy for low-lying rectal cancer (as it is routinely performed after low anterior resection), which can prevent sequences of rectal perforation, is dependent on further identification of patients with higher risk. That necessitates conduct of further research.

- Management of rectal perforation varies according to the degree and site of perforation and ranges from conservative management to emergency surgical intervention.
Perforation of a rectal tumour is a rare but life-threatening complication and has so far been reported in only one single case series. $^{2}$ That case was owing to tumour necrosis and subsequent perforation. This case report is the first to report perforation through the irradiated rectum away from tumour site.

There are five types of perforations described: incomplete, through anal canal, into retroperitoneum, transmural into adjacent organs and directly into the peritoneal cavity. ${ }^{3}$ The site of the perforation determines the expected clinical signs as well as the clinical management, ranging from simple observation and drainage of collection to immediate surgical exploration. It is very important to highlight the site factor in the consent process as well as when considering temporary diversion of the stoma in selective cases before neoadjuvant therapy, which is further dependent on risk assessment of the patient. This can help prevent consequences of rectal perforation in such cases, which can be a subject for future research. It is worth mentioning that rectal tumour perforation is considered a risk factor for recurrence, which can change the management of patients regarding adjuvant chemotherapy, and can also affect the surveillance programme postoperatively, according to $\mathrm{NCCN}$ guidelines. ${ }^{1}$

Contributors KE involved in the case scenario, literature review and final revision. Competing interests None.

Patient consent Obtained.

Provenance and peer review Not commissioned; externally peer reviewed.

\section{REFERENCES}

1 NCCN clinical practice guidelines in oncology: Rectal Cancer, version 3. 2014. http:// www.nccn.org/professionals/physician_gls/pdf/rectal.pdf

2 Lee J, Chen F, Steel M, et al. Perforated rectal cancer associated with neoadjuvant radiotherapy: report of four cases. Dis Colon Rectum 2006;49:1629-32. PMID: 17039387

3 de Feiter PW, Soeters PB, Dejong $\mathrm{CH}$. Rectal perforations after barium enema: a review. Dis Colon Rectum 2006:49:261-71. PMID: 16328608 
Copyright 2015 BMJ Publishing Group. All rights reserved. For permission to reuse any of this content visit http://group.bmj.com/group/rights-licensing/permissions.

BMJ Case Report Fellows may re-use this article for personal use and teaching without any further permission.

Become a Fellow of BMJ Case Reports today and you can:

- Submit as many cases as you like

- Enjoy fast sympathetic peer review and rapid publication of accepted articles

- Access all the published articles

- Re-use any of the published material for personal use and teaching without further permission

For information on Institutional Fellowships contact consortiasales@bmjgroup.com

Visit casereports.bmj.com for more articles like this and to become a Fellow 